\title{
The clinical utilization of radiation therapy in Korea between 2009 and 2013
}

\author{
Jin-Kyu Kang, MD¹, Mi-Sook Kim, MD, PhD²,2, Won-II Jang, MD¹, Young Seok Seo, MD¹, Hee Jin Kim², \\ Chul Koo Cho, MD, PhD', Hyung Jun Yoo, MD¹, Eun Kyung Paik, MD¹, Yu Jin Cha, MD¹, \\ Hyun Jin Song, MPharm, PhD ${ }^{3}$ \\ 'Department of Radiation Oncology and, ${ }^{2}$ Radiation Medicine Policy Development Center, Korea Institute of Radiological \& \\ Medical Sciences, Seoul ${ }^{3}$ College of Pharmacy and Research Institute of Pharmaceutical Sciences, \\ Kyungpook National University, Daegu, Korea
}

Purpose: The purpose of this study was to estimate the clinical utilization of radiation therapy (RT) in Korea between 2009 and 2013.

Materials and Methods: We analyzed open claims data from the Health Insurance Review and Assessment Service. The subjects were patients who had diagnostic codes C00-C97 or D00-D48 according to the 10th revision of the International Classification of Diseases, with procedure codes indicating RT treatment.

Results: The total number of patients who received RT in 2009, 2010, 2011, 2012, and 2013 were 45,571, 49,593, 54,671, 59,172, and 61,485 , respectively. Among them, the total numbers of male and female patients were $20,780 / 24,791$ in 2009, 22,711/26,882 in $2010,24,872 / 29,799$ in $2011,27,101 / 32,071$ in 2012 , and $27,941 / 33,544$ in 2013 . The five cancers that were most frequently treated with RT between 2009 and 2012 were breast, lung, colorectal, liver, and uterine cervical cancers. However, the fifth most common cancer treated with RT that replaced uterine cervical cancer in 2013 was prostate cancer. The three leading types of cancer among the male patients were lung, colorectal, and liver cancers, whereas in female patients, they were breast, uterine cervical, and lung cancers. The type of cancer most commonly treated by RT was cancer of the central nervous system in patients aged 20 years or less, breast cancer in patients aged 30-50 years, and lung cancer in patients aged 60 years or more.

Conclusion: Data from this study provided the clinical utilization of RT in Korea between 2009 and 2013.

Keywords: Neoplasms, Radiotherapy, Statistics, Korea

\section{Introduction}

Cancer is a major public health problem in Korea. According to the annual report of the Korea Central Cancer Registry, more than 200,000 people have been diagnosed with cancer every year since 2010, with a steadily increasing cancer incidence
[1-4]. This trend is expected to persist in the future because of population aging, westernized lifestyle, development of diagnostic tools that can detect cancer, and a medical system that encourages cancer screening [5-6].

As radiation therapy (RT) is an indispensable part of cancer treatment, it is reasonable and necessary to estimate the

Received 1 April 2016, Revised 23 May 2016, Accepted 17 June 2016.

Correspondence: Mi-Sook Kim, MD, PhD, Department of Radiation Oncology, Korea Institute of Radiological \& Medical Sciences, 75 Nowon-ro, Nowon-gu, Seoul 01812, Korea. Tel: +82-2-970-2484, Fax: +82-2-970-2412, E-mail: mskim@kirams. re.kr

(c) This is an Open Access article distributed under the terms of the Creative Commons Attribution Non-Commercial License (http://creativecommons.org/ licenses/by-nc/4.0/) which permits unrestricted non-commercial use, distribution, and reproduction in any medium, provided the original work is properly cited.

www.e-roj.org 
clinical utilization of RT for understanding the status and development of cancer treatment in Korea. The most up to date official records on the clinical utilization of RT in Korea were reported for the period 1999-2006 [7-10]. These records were compiled using questionnaire-based methods over a long period and possibly had recall bias. Recently, we reported the findings of a pilot study for the clinical utilization of RT in 2009 and 2013 [11] in order to estimate the feasibility of statistics using claims data from the Health Insurance Review and Assessment Service (HIRA). In previous studies [7-11], we categorized patients according to the cancer site treated by $\mathrm{RT}$, instead of their primary cancer diagnostic codes. In the present study, the patients were categorized according to their primary cancer codes rather than their metastasis status or the site of treatment. Moreover, a previous study [11] analyzed patients who only had ' $\mathrm{C}$ ' code diseases. Patients who had ductal carcinoma in situ of the breast or benign brain tumor treated with RT could not be included in the total count of patients who received RT because they are 'D' code diseases and are therefore classified as benign. Consequently, the actual total number of patients who received RT was underestimated. Therefore, in the present study, we analyzed the data from patients having both ' $\mathrm{D}$ ' code and ' $\mathrm{C}$ ' code diseases. The aim of the present study was to estimate the clinical utilization of RT in the 2009-2013 period using claims data from the HIRA.

\section{Materials and Methods}

The detailed methods using claims data from the HIRA are described in a previous study [11]. The customized source population criteria for this study are shown in Table 1. In this study, we included not only patients with International Classification of Disease 10 (ICD-10) diagnostic codes C00-C97, but also those with diagnostic codes D00-D48 (including carcinoma in situ or benign neoplasms), who were also associated with at least one of the procedure codes related to RT treatment. In our previous study, we categorized

Table 1. The customized source population

\begin{tabular}{ll}
\hline \multicolumn{1}{c}{ List } & \multicolumn{1}{c}{ Criterion } \\
\hline Treatment period & 01/01/2009-12/31/2013 \\
Type of healthcare facility & Tertiary, secondary \\
Diagnostic code & C00-C97, D00-D48 \\
Type of insurance & Health insurance, medical aid \\
Hospital region & National \\
Sex & Male, female \\
Age & All ages \\
\hline
\end{tabular}

Table 2. Procedure codes related to radiation therapy

\begin{tabular}{ll}
\hline \multicolumn{1}{c}{ Procedure code } & \multicolumn{1}{c}{ Name of procedure code } \\
\hline HD51-HD56 & Teletherapy-single or opposed ports \\
HD58-HD59 & Rotational irradiation \\
HD61 & 3-Dimensional conformal therapy \\
HD80-HD89 & Brachytherapy \\
HD91 & Total body irradiation \\
HD92 & Total body lymph node irradiation \\
HD110-HD115, & Total skin electron beam therapy \\
HD211-HD212 & Stereotactic radiation therapy \\
HD121 & \\
HZ271 & Proton therapy \\
\hline
\end{tabular}

the patients who had diagnostic codes for metastasis (C7779) based on whether they received RT to the metastatic site, irrespective of the patient's primary cancer diagnostic code. However, in this study, the patients were categorized according to their primary cancer codes rather than their metastasis status, even if they had diagnostic codes indicating metastasis. For example, if the patient had code C34 for primary lung cancer and code C79.30 for brain metastasis, the patient was categorized as having primary lung cancer instead of brain metastasis. This method of categorization was to identify the number of patients who underwent RT for their primary cancers. However, if the patient only had a diagnostic code for metastasis, we could not determine the primary cancer diagnosis; therefore, the patient was categorized as 'unknown primary.' If the patient had both $\mathrm{C}$ and $\mathrm{D}$ diagnostic codes, it was assumed the patient had received RT for the disease with the $\mathrm{C}$ diagnostic code.

We analyzed the claims data from the HIRA in order to identify the total number of patients who underwent RT, and the number of patients who received RT by primary cancer diagnosis, gender, and age group between 2009 and 2013 in Korea. In addition, through the classification of the procedure codes (Table 2), we estimated the total number of patients who received specific RT modalities, including brachytherapy, intensity-modulated radiation therapy (IMRT), stereotactic radiation therapy (SRT), and proton therapy.

\section{Results}

The total number of patients who received RT in 2009, 2010, 2011, 2012, and 2013 were 45,571, 49,593, 54,671, 59,172, and 61,485 , respectively (Fig. 1). Among them, the total number of cancer patients (C00-C97) who received RT in 2009, 2010, 


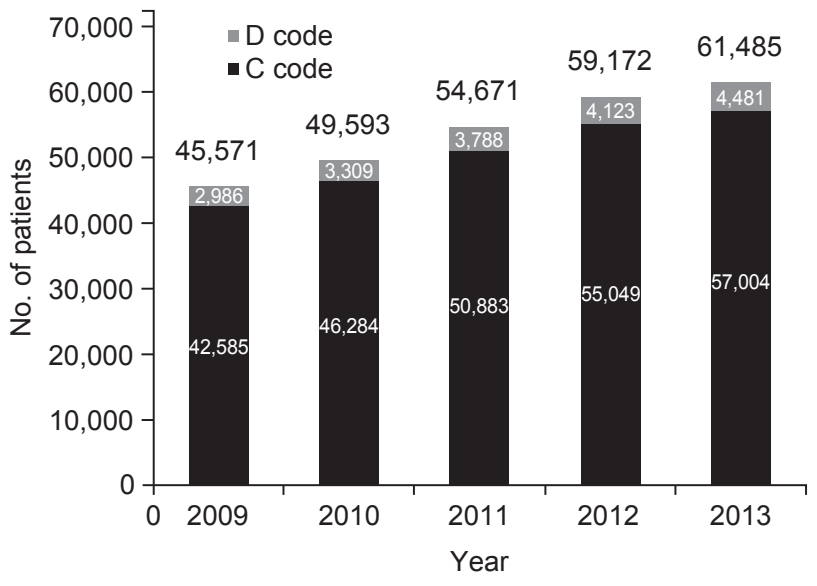

Fig. 1. The total number of patients who underwent radiation therapy between 2009 and 2013 in Korea.

2011, 2012, and 2013 were 42,585, 46,248, 50,883, 55,049, and 57,004 , respectively. The total numbers of male and female patients who received RT were 20,780/24,791 in 2009, $22,711 / 26,882$ in $2010,24,872 / 29,799$ in $2011,27,101 / 32,071$ in 2012, and 27,941/33,544 in 2013 (Fig. 2). The distribution of patients who received RT by cancer diagnosis between 2009 and 2013 is shown in Table 3. The five most common cancers treated with RT between 2009 and 2012 were breast, lung, colorectal, liver, and uterine cervical cancers. However, the fifth most common cancer treated with RT in 2013 was

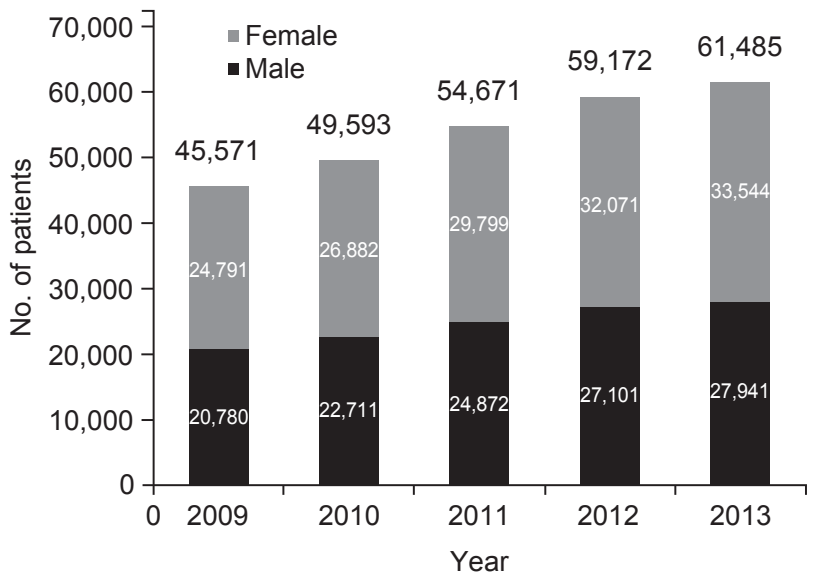

Fig. 2. The total numbers of male and female patients who received radiation therapy between 2009 and 2013 in Korea.

prostate cancer instead of uterine cervical cancer. The three leading types of cancer among male patients were lung, colorectal, and liver cancers, and those among female patients were breast, uterine cervical, and lung cancers. Breast cancer patients constituted a quarter of the total number of cancer patients who underwent $R T$, and approximately half of the female cancer patients. Carcinoma in situ of the breast treated with RT was the most common among the diseases with code 'D.' The benign neoplasms of the meninges and the central nervous system were second and third most common among

Table 3. The distribution of cancer patients who underwent radiation therapy based on primary diagnosis between 2009 and 2013

\begin{tabular}{|c|c|c|c|c|c|c|}
\hline \multirow{2}{*}{ Category } & \multirow{2}{*}{ Primary diagnosis (diagnostic code) } & \multicolumn{5}{|c|}{ No. of patients who received radiation therapy } \\
\hline & & 2009 & 2010 & 2011 & 2012 & 2013 \\
\hline Breast & (C50) & 11,111 & 12,226 & 13,724 & 14,956 & 15,655 \\
\hline \multirow[t]{10}{*}{ Gastrointestinal } & Colorectum (C18-C20) & 4,323 & 4,561 & 5,033 & 5,004 & 4,860 \\
\hline & Liver (C22) & 2,719 & 2,757 & 3,015 & 3,424 & 3,595 \\
\hline & Esophagus (C15) & 1,106 & 1,179 & 1,236 & 1,327 & 1,374 \\
\hline & Stomach (C16) & 912 & 1,016 & 1,077 & 1,034 & 1,012 \\
\hline & Pancreas (C25) & 566 & 678 & 780 & 940 & 901 \\
\hline & Gallbladder \& biliary (C23-C24) & 691 & 714 & 772 & 842 & 874 \\
\hline & Anus (C21) & 146 & 165 & 188 & 220 & 211 \\
\hline & Small bowel (C17) & 28 & 35 & 39 & 40 & 42 \\
\hline & Other (C26) & 5 & 2 & 3 & 4 & 3 \\
\hline & Subtotal & 10,496 & 11,107 & 12,143 & 12,835 & 12,872 \\
\hline \multirow[t]{6}{*}{ Thoracic } & Lung (C34) & 7,379 & 8,238 & 8,861 & 9,285 & 9,980 \\
\hline & Thymus (C37) & 190 & 221 & 266 & 235 & 245 \\
\hline & Mediastinum (C38) & 43 & 42 & 39 & 46 & 47 \\
\hline & Trachea (C33) & 14 & 21 & 16 & 18 & 17 \\
\hline & Other (C39) & 3 & 1 & 5 & 2 & 1 \\
\hline & Subtotal & 7,629 & 8,523 & 9,187 & 9,586 & 10,290 \\
\hline
\end{tabular}

Continued on the next page. 
Table 3. Continued

\begin{tabular}{|c|c|c|c|c|c|c|}
\hline \multirow{2}{*}{ Category } & \multirow{2}{*}{ Primary diagnosis (diagnostic code) } & \multicolumn{5}{|c|}{ No. of patients who received radiation therapy } \\
\hline & & 2009 & 2010 & 2011 & 2012 & 2013 \\
\hline \multirow[t]{12}{*}{ Head \& neck } & Larynx (C32) & 730 & 803 & 761 & 872 & 955 \\
\hline & Oropharynx (C01, C09-C10) & 340 & 398 & 496 & 611 & 588 \\
\hline & Oral cavity (C02-C06) & 362 & 412 & 502 & 598 & 583 \\
\hline & Nasopharynx (C11) & 307 & 300 & 409 & 493 & 484 \\
\hline & Salivary gland (C07-C08) & 259 & 276 & 291 & 350 & 344 \\
\hline & Hypopharynx (C12-C13) & 287 & 287 & 361 & 392 & 336 \\
\hline & Paranasal sinus (C31) & 106 & 144 & 150 & 167 & 148 \\
\hline & Nasal cavity (C30) & 81 & 67 & 96 & 124 & 113 \\
\hline & Eye \&t orbit (C69) & 35 & 36 & 44 & 52 & 49 \\
\hline & Lip (CO0) & 12 & 8 & 12 & 9 & 14 \\
\hline & Other (C14) & 7 & 13 & 19 & 22 & 16 \\
\hline & Subtotal & 2,526 & 2,744 & 3,141 & 3,690 & 3,630 \\
\hline \multirow[t]{6}{*}{ Gynecologic } & Uterine cervix (C53) & 2,439 & 2,441 & 2,450 & 2,470 & 2,545 \\
\hline & Uterine corpus (C54-C55) & 633 & 588 & 628 & 715 & 737 \\
\hline & Ovary \& tubes (C56) & 143 & 183 & 206 & 200 & 240 \\
\hline & Vagina \&t vulva (C51-C52) & 105 & 119 & 110 & 114 & 94 \\
\hline & Other (C57-C58) & 7 & 13 & 13 & 14 & 10 \\
\hline & Subtotal & 3,327 & 3,344 & 3,407 & 3,513 & 3,626 \\
\hline \multirow[t]{6}{*}{ Genitourinary } & Prostate (C61) & 1,222 & 1,446 & 1,937 & 2,426 & 2,552 \\
\hline & Ureter \&t bladder (C66-C67) & 360 & 429 & 496 & 480 & 523 \\
\hline & Kidney (C64-C65) & 294 & 359 & 426 & 405 & 433 \\
\hline & Penis \&t testis (C60, C62-C63) & 51 & 65 & 65 & 53 & 66 \\
\hline & Other (C68) & 8 & 9 & 8 & 13 & 12 \\
\hline & Subtotal & 1,935 & 2,308 & 2,932 & 3,377 & 3,586 \\
\hline \multirow[t]{4}{*}{ CNS } & Brain (C70-C71) & 1,365 & 1,448 & 1,386 & 1,508 & 1,577 \\
\hline & Spinal cord (C72) & 44 & 44 & 61 & 57 & 55 \\
\hline & Other (C47) & 29 & 35 & 47 & 37 & 50 \\
\hline & Subtotal & 1,438 & 1,527 & 1,494 & 1,602 & 1,682 \\
\hline \multirow[t]{4}{*}{ Lymphoma } & Non-Hodgkin's lymphoma (C82-C88) & 1,056 & 1,203 & 1,177 & 1,325 & 1,316 \\
\hline & Hodgkin's disease (C81) & 86 & 98 & 99 & 108 & 91 \\
\hline & Other (C96) & 6 & 4 & 21 & 21 & 22 \\
\hline & Subtotal & 1,148 & 1,305 & 1,297 & 1,454 & 1,429 \\
\hline Soft tissue & $(C 46, C 49)$ & 406 & 506 & 540 & 571 & 619 \\
\hline Myeloma \&t plasmacytoma & (C90) & 324 & 338 & 315 & 410 & 438 \\
\hline Thyroid & (C73) & 305 & 340 & 357 & 388 & 358 \\
\hline Leukemia & (C91-C95) & 333 & 367 & 357 & 351 & 352 \\
\hline Skin & $(\mathrm{C} 44)$ & 205 & 224 & 240 & 273 & 265 \\
\hline Malignant melanoma & (C43) & 148 & 159 & 203 & 207 & 214 \\
\hline Primary bone \&t cartilage & (C40-C41) & 157 & 179 & 211 & 218 & 169 \\
\hline Endocrine & (C74-C75) & 71 & 66 & 51 & 76 & 91 \\
\hline Unknown primary & (C45,C48, C76-C80, C97) & 1,026 & 1,021 & 1,284 & 1,542 & 1,728 \\
\hline Total no. of cancer patients & - & 42,585 & 46,284 & 50,883 & 55,049 & 57,004 \\
\hline Carcinoma in situ of the breast & (D05) & 939 & 1,128 & 1,355 & 1,601 & 1,870 \\
\hline Benign neoplasm of meninges & (D32) & 867 & 859 & 1,013 & 954 & 1,027 \\
\hline Benign neoplasm of CNS & (D33) & 616 & 639 & 720 & 734 & 731 \\
\hline Benign neoplasm of endocrine & (D34-D35) & 197 & 260 & 227 & 276 & 300 \\
\hline Other $D$ code diseases & (D00-D04, D06-D31, D36-D48) & 367 & 423 & 473 & 558 & 553 \\
\hline Total D code patients & - & 2,986 & 3,309 & 3,788 & 4,123 & 4,481 \\
\hline Total & - & 45,571 & 49,593 & 54,671 & 59,172 & 61,485 \\
\hline
\end{tabular}

CNS, central nervous system. 
Table 4. The number of patients who underwent radiation therapy by cancer diagnosis and age group in 2013

\begin{tabular}{|c|c|c|c|c|c|c|c|}
\hline \multirow{2}{*}{ Primary diagnosis } & \multicolumn{7}{|c|}{ No. of patients who received radiation therapy by age group } \\
\hline & 20's or under & 30's & 40 's & 50 's & 60 's & 70's or older & Total \\
\hline Breast (C50) & 151 & 1,600 & 5,705 & 5,157 & 2,203 & 839 & 15,655 \\
\hline Colorectum (C18-C20) & 13 & 146 & 549 & 1,366 & 1,392 & 1,394 & 4,860 \\
\hline Liver (C22) & 4 & 78 & 433 & 1,211 & 1,106 & 763 & 3,595 \\
\hline Esophagus (C15) & 0 & 2 & 55 & 345 & 416 & 556 & 1,374 \\
\hline Stomach (C16) & 7 & 57 & 134 & 279 & 278 & 257 & 1,012 \\
\hline Pancreas (C25) & 1 & 12 & 75 & 238 & 318 & 257 & 901 \\
\hline Gallbladder \& biliary (C23-C24) & 0 & 8 & 51 & 213 & 312 & 290 & 874 \\
\hline Anus (C21) & 0 & 7 & 19 & 61 & 58 & 66 & 211 \\
\hline Small bowel (C17) & 1 & 2 & 9 & 11 & 10 & 9 & 42 \\
\hline Other (C26) & 0 & 1 & 0 & 0 & 1 & 1 & 3 \\
\hline Subtotal & 26 & 313 & 1,325 & 3,724 & 3,891 & 3,593 & 12,872 \\
\hline Lung (C34) & 13 & 126 & 624 & 2,182 & 3,280 & 3,755 & 9,980 \\
\hline Thymus (C37) & 5 & 23 & 58 & 56 & 67 & 36 & 245 \\
\hline Mediastinum (C38) & 7 & 6 & 8 & 11 & 11 & 4 & 47 \\
\hline Trachea (C33) & 2 & 0 & 5 & 3 & 2 & 5 & 17 \\
\hline Other (C39) & 0 & 0 & 0 & 0 & 0 & 1 & 1 \\
\hline Subtotal & 27 & 155 & 695 & 2,252 & 3,360 & 3,801 & 10,290 \\
\hline Larynx (C32) & 1 & 5 & 36 & 230 & 330 & 353 & 955 \\
\hline Oropharynx (C01, C09-C10) & 3 & 14 & 80 & 214 & 170 & 107 & 588 \\
\hline Oral cavity (CO2-C06) & 14 & 33 & 88 & 157 & 145 & 146 & 583 \\
\hline Nasopharynx (C11) & 19 & 55 & 93 & 150 & 110 & 57 & 484 \\
\hline Salivary gland (C07-C08) & 19 & 30 & 58 & 101 & 82 & 54 & 344 \\
\hline Hypopharynx (C12-C13) & 0 & 1 & 22 & 77 & 124 & 112 & 336 \\
\hline Paranasal sinus (C31) & 4 & 8 & 18 & 40 & 42 & 36 & 148 \\
\hline Nasal cavity (C30) & 6 & 9 & 17 & 31 & 25 & 25 & 113 \\
\hline Eye \&t orbit (C69) & 4 & 3 & 10 & 14 & 7 & 11 & 49 \\
\hline Lip (CO0) & 0 & 0 & 1 & 3 & 3 & 7 & 14 \\
\hline Other (C14) & 0 & 0 & 1 & 1 & 4 & 10 & 16 \\
\hline Subtotal & 70 & 158 & 424 & 1,018 & 1,042 & 918 & 3,630 \\
\hline Uterine cervix (C53) & 49 & 273 & 603 & 724 & 381 & 515 & 2,545 \\
\hline Uterine corpus (C54-C55) & 0 & 19 & 106 & 325 & 201 & 86 & 737 \\
\hline Ovary \&t tubes (C56) & 6 & 12 & 50 & 98 & 55 & 19 & 240 \\
\hline Vagina \&t vulva (C51-C52) & 2 & 3 & 8 & 17 & 19 & 45 & 94 \\
\hline Other (C57-C58) & 1 & 1 & 0 & 4 & 4 & 0 & 10 \\
\hline Subtotal & 58 & 308 & 767 & 1,168 & 660 & 665 & 3,626 \\
\hline Prostate (C61) & 0 & 0 & 22 & 265 & 868 & 1,397 & 2,552 \\
\hline Ureter \& bladder (C66-C67) & 2 & 2 & 25 & 65 & 138 & 291 & 523 \\
\hline Kidney (C64-C65) & 13 & 14 & 44 & 121 & 114 & 127 & 433 \\
\hline Penis \&t testis (C60, C62-C63) & 13 & 18 & 14 & 7 & 6 & 8 & 66 \\
\hline Other (C68) & 0 & 0 & 0 & 1 & 4 & 7 & 12 \\
\hline Subtotal & 28 & 34 & 105 & 459 & 1,130 & 1,830 & 3,586 \\
\hline Brain (C70-C71) & 270 & 150 & 281 & 340 & 298 & 238 & 1,577 \\
\hline Spinal cord (C72) & 15 & 6 & 12 & 6 & 5 & 11 & 55 \\
\hline Other (C47) & 15 & 8 & 6 & 10 & 7 & 4 & 50 \\
\hline Subtotal & 300 & 164 & 299 & 356 & 310 & 253 & 1,682 \\
\hline Non-Hodgkin's lymphoma (C82-C88) & 87 & 115 & 211 & 347 & 262 & 294 & 1,316 \\
\hline Hodgkin's disease (C81) & 44 & 15 & 8 & 13 & 4 & 7 & 91 \\
\hline Other (C96) & 6 & 1 & 4 & 3 & 2 & 6 & 22 \\
\hline Subtotal & 137 & 131 & 223 & 363 & 268 & 307 & 1,429 \\
\hline
\end{tabular}


Table 4. Continued

\begin{tabular}{|c|c|c|c|c|c|c|c|}
\hline \multirow{2}{*}{ Primary diagnosis } & \multicolumn{7}{|c|}{ No. of patients who received radiation therapy by age group } \\
\hline & 20's or under & 30's & 40 's & 50 's & 60 's & 70's or older & Total \\
\hline Soft tissue $(\mathrm{C} 46, \mathrm{C} 49)$ & 82 & 61 & 86 & 133 & 120 & 137 & 619 \\
\hline Myeloma \&t plasmacytoma (C90) & 0 & 11 & 38 & 110 & 146 & 133 & 438 \\
\hline Thyroid (C73) & 8 & 15 & 45 & 92 & 78 & 120 & 358 \\
\hline Leukemia (C91-C95) & 151 & 71 & 51 & 49 & 25 & 5 & 352 \\
\hline Skin (C44) & 4 & 13 & 26 & 41 & 52 & 129 & 265 \\
\hline Malignant melanoma (C43) & 2 & 12 & 32 & 68 & 52 & 48 & 214 \\
\hline Primary bone \& cartilage (C40-C41) & 49 & 15 & 26 & 38 & 22 & 19 & 169 \\
\hline Endocrine (C74-C75) & 37 & 4 & 12 & 11 & 13 & 14 & 91 \\
\hline Unknown primary $(\mathrm{C} 45, \mathrm{C} 48, \mathrm{C} 76-\mathrm{C} 80, \mathrm{C} 97)$ & 30 & 61 & 235 & 463 & 508 & 431 & 1,728 \\
\hline Total & 1,160 & 3,126 & 10,094 & 15,502 & 13,880 & 13,242 & 57,004 \\
\hline
\end{tabular}

Table 5. The distribution of patients who received radiation therapy according to specific radiation therapy modalities

\begin{tabular}{lccrrr}
\hline \multicolumn{1}{c}{ Radiation therapy modality } & \multicolumn{3}{c}{ Year } \\
\cline { 2 - 6 } & 2009 & 2010 & 2011 & 2012 & 2013 \\
\hline Brachytherapy & 1,441 & 1,376 & 1,384 & 1,401 & 1,387 \\
Intensity-modulated radiation therapy & - & - & 3,113 & 6,648 & 6,747 \\
Stereotactic radiation therapy & 4,226 & 4,894 & 5,435 & 5,543 & 5,945 \\
Proton therapy & - & - & 25 & 50 & 33 \\
\hline
\end{tabular}

the diseases with code 'D'.

The distribution of patients who received RT in 2013 based on cancer diagnosis and age group is shown in Table 4. The most common cancer was that of the central nervous system for patients aged 20 years or less, while breast cancer was the most common cancer in patients aged $30-50$ years, and lung cancer was the most common cancer in patients aged 60 years or more. Similar trends were observed for previous years.

The distribution of patients who received RT with specific modalities is shown in Table 5 . Because National health insurance had not covered IMRT and proton therapy before 2011, the number of patients who received IMRT and proton therapy before 2011 was not calculated.

\section{Discussion and Conclusion}

This study was conducted to analyze the clinical utilization of RT between 2009 and 2013 in Korea using claims data from the HIRA. The total number of patients who underwent RT increased 4\%-10\% per year between 2009 and 2013 (Fig. 1). Considering the annual cancer incidence $[1-4,12]$, although the percentage of patients who underwent RT increased from 23\% to 27\% during these 5 years, it remained below 30\% (Fig. 3). Table 6 shows the utilization rate of RT, which is defined as

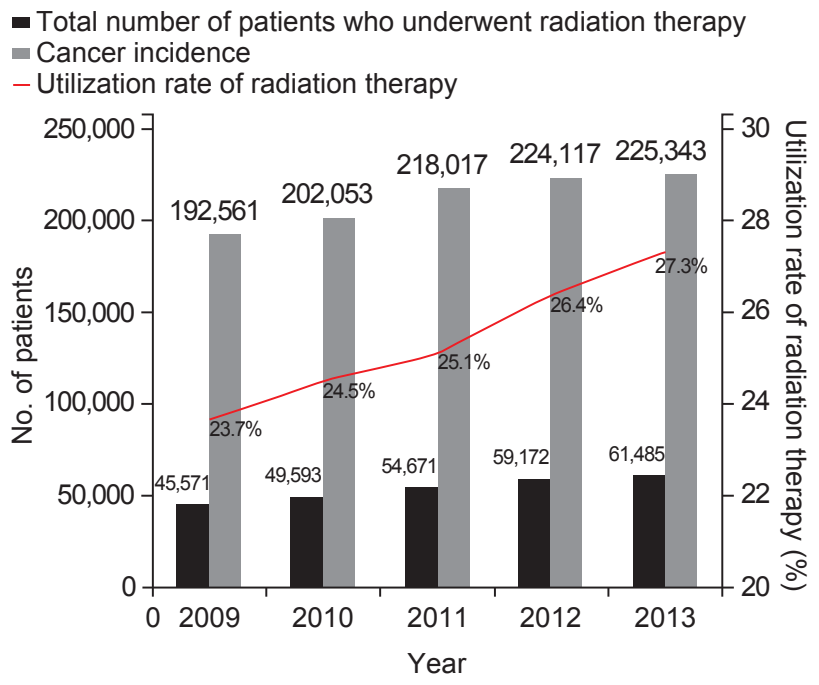

Fig. 3. Cancer incidence and the total number of patients who received radiation therapy between 2009 and 2013 in Korea.

the proportion of all cancers with indications for RT by country [13-17]. This value can be dependent on the distributions of cancer types and stages. According to these reports, about $47 \%-55 \%$ of cancer patients in developed or developing countries would be candidates for RT treatment. Although the optimal utilization rate of RT in Korea was not reported yet, 
Table 6. List of relevant studies conducted on the utilization rates of radiation therapy by country

\begin{tabular}{lllc}
\hline \multicolumn{1}{c}{ Author } & Year & \multicolumn{1}{c}{ Country } & $\begin{array}{c}\text { Optimal utilization rate of } \\
\text { radiation therapy (\%) }\end{array}$ \\
\hline Delaney et al. [13] & 2005 & Australia & 52.3 \\
Jaen Olasolo et al. [14] & 2007 & Spain & 55.0 \\
Barton et al. [15] & 2014 & Australia & 48.3 \\
Borras et al. [16] & 2015 & 40 European countries & $47.0-53.2$ \\
Rosenblatt et al. [17] & 2015 & Ghana, Philippines, Tunisia, Serbia, Costa Rica, & $47.0-56.0$ \\
& & Romania, Malaysia, Uruguay, Slovenia & \\
\hline
\end{tabular}

it is estimated to be within the same range. Even though the optimal RT utilization rate has been criticized for potentially overestimating the demand for RT [18], the clinical utilization rate of RT in Korea could be estimated to be much lower than the optimal utilization rate of RT.

Generally, the number of cancer patients who underwent RT for primary cancer increased steadily; however, the number of uterine cervical cancer patients remained approximately at 2,500 during these 5 years. While, the number of prostate cancer patients who received RT notably increased during this period, and consequently, prostate cancer became the fifth most common cancer in 2013 replacing the cervical cancer. This might not only be attributed to the increased prevalence of prostate cancer, but also to the improvement of RT techniques including IMRT or SRT.

In terms of RT modalities, while the numbers of patients who received brachytherapy were similar for each year between 2009 and 2013, the cases receiving IMRT notably increased from 2011 to 2013, and this increase is expected to continue in the future because of national health insurance coverage of IMRT. Similar to IMRT, the number of cases treated with SRT also has steadily increased during these 5 years. Because the claims data from the HIRA only included that of the insured cases and the number of uninsured treatments could not be recorded, the actual number of patients who received proton therapy is expected to be more than the reported number.

In comparison to the results from a previous study [11], differences were observed in the total number of patients who underwent RT in 2009 and 2013. One of the reasons for the difference could be attributed to the different collection time of claims data from the HIRA, considering that some patients' data are registered after 1 or more years. Therefore, the total number of patients who received RT in the same year might not indicate the actual number.

This study could provide useful clinical utilization data for $\mathrm{RT}$ in Korea, and we aim to continuously provide the results on the clinical utilization of RT using claims data from the HIRA in the form of an annual report in the future.

\section{Conflict of Interest}

No potential conflict of interest relevant to this article was reported.

\section{Acknowledgments}

This work was supported by the National Nuclear RetD program of the Ministry of Education, Science and Technology, Republic of Korea.

\section{References}

1. Jung KW, Won YJ, Kong HJ, Oh CM, Seo HG, Lee JS. Cancer statistics in Korea: incidence, mortality, survival and prevalence in 2010. Cancer Res Treat 2013;45:1-14.

2. Jung KW, Won YJ, Kong HJ, Oh CM, Lee DH, Lee JS. Cancer statistics in Korea: incidence, mortality, survival, and prevalence in 2011. Cancer Res Treat 2014;46:109-23.

3. Jung KW, Won YJ, Kong HJ, et al. Cancer statistics in Korea: incidence, mortality, survival, and prevalence in 2012. Cancer Res Treat 2015;47:127-41.

4. Oh CM, Won YJ, Jung KW, et al. Cancer statistics in Korea: incidence, mortality, survival, and prevalence in 2013. Cancer Res Treat 2016;48:436-50.

5. Lee TJ, Kim S, Cho HJ, Lee JH. The incidence of thyroid cancer is affected by the characteristics of a healthcare system. J Korean Med Sci 2012;27:1491-8.

6. Suh $M$, Choi KS, Park B, et al. Trends in cancer screening rates among Korean men and women: results of the Korean National Cancer Screening Survey, 2004-2013. Cancer Res Treat 2016:48:1-10.

7. Yoo SY, Kim MS, Ji YH, Cho CK, Yang KM, You HJ. Statistics for Department of Radiation Oncology (1999-2001). J Korean Soc Ther Radiol Oncol 2004;22:234-6. 
8. Kim MS, Ji YH, You SY, Cho CK, Yang KM, Ryu HJ. National statistics of radiation oncology in Korea (2002-2004). J Korean Soc Ther Radiol Oncol 2006;24:77-80.

9. Kim MS, Ji YH, You SY, et al. National statistics of radiation oncology in Korea (2005). J Korean Soc Ther Radiol Oncol 2006;24:207-9.

10. Ji YH, Kim MS, You SY, You DH, Choi MS, Jung HJ. National statistics of radiation oncology in Korea (2006). J Korean Soc Ther Radiol Oncol 2008;26:131-3.

11. Kang JK, Kim MS, Jang WI, et al. The clinical status of radiation therapy in Korea in 2009 and 2013. Cancer Res Treat 2015 Dec 14 [Epub]. http://dx.doi.org/10.4143/crt.2015.370.

12. Jung KW, Park $\mathrm{S}$, Kong HJ, et al. Cancer statistics in Korea: incidence, mortality, survival, and prevalence in 2009. Cancer Res Treat 2012;44:11-24.

13. Delaney $G$, Jacob S, Featherstone $C$, Barton $M$. The role of radiotherapy in cancer treatment: estimating optimal utilization from a review of evidence-based clinical guidelines. Cancer 2005;104:1129-37.
14. Jaen Olasolo J, Alonso Redondo E, Exposito Hernandez J, de las Penas Cabrera MD, Cabrera Roldan P. Evidence-based estimation and radiotherapy utilisation rate in Andalusia. Clin Transl Oncol 2007;9:789-96.

15. Barton MB, Jacob S, Shafiq J, et al. Estimating the demand for radiotherapy from the evidence: a review of changes from 2003 to 2012. Radiother Oncol 2014;112:140-4.

16. Borras JM, Lievens $Y$, Dunscombe $P$, et al. The optimal utilization proportion of external beam radiotherapy in European countries: an ESTRO-HERO analysis. Radiother Oncol 2015;116:38-44.

17. Rosenblatt $E$, Barton $M$, Mackillop W, et al. Optimal radiotherapy utilisation rate in developing countries: an IAEA study. Radiother Oncol 2015;116:35-7.

18. Mackillop WJ, Kong W, Brundage $M$, et al. A comparison of evidence-based estimates and empirical benchmarks of the appropriate rate of use of radiation therapy in Ontario. Int J Radiat Oncol Biol Phys 2015;91:1099-107. 